\title{
Non-stenotic coronary lesion — is it really non-ischemic?
}

\author{
Alexander Kiško"*, Marika Vereb² \\ ${ }^{1}$ Faculty of Health Care, Prešov University in Prešov, Sekčov Polyclinic, Prešov, Slovak Republic \\ ${ }^{2}$ Nuclear medicine, Sekčov Polyclinic, Prešov, Slovak Republic
}

Coronary angiography has a diagnostic limitation in identifying non-stenotic coronary lesion (NSCL) responsible for ischemia. Although an abnormal fractional flow reserve (FFR) increases the probability of significant obstructive lesions, it cannot reliably distinguish intermediate epicardial stenosis from ischemic, diffuse atherosclerosis or microvascular disease. Myocardial perfusion defects in patients (pts) with NSCL have often been unreasonably considered by invasive cardiologists to be "falsely positive".

We evaluated a prognostic value of gated single-photon emission computed tomography (SPECT) myocardial perfusion imaging (MPI) in unselected group of the pts with NSCL over a 24 month period of follow-up. 170 pts (115 males, $67.6 \%$; aged $42-68$; mean age $56.4 \pm 9.2$ years) with NSCL (stenosis of $50 \%$ or less of left anterior descending artery and $70 \%$ or less of any other coronary artery or its major branches, FFR cut-off 0.80) were enrolled into the study. Retrospective analysis of 86 pts with NSCL and subsequent

\section{Received: $17^{\text {th }}$ Apr 2014}

*Address for correspondence: Faculty of Health Care, Prešov University in Prešov, Prešov, Sekčov Polyclinic, 080 01, Prešov, Jurkovičova 19, Slovak Republic.

Phone: +421907439977

E-mail: alexander.kisko@unipo.sk positive MPS performed within 6 months from the time of coronary angiography (study group) and 84 pts with normal scan results (control group) was performed. The follow-up period lasted for 24 months from the time of MPI or up to the time of major coronary event (MCE) - first occurrence of cardiac death or myocardial infarction. Over a two-year follow-up, approximately $11 \%$ of the pts in the study group had MCE as compared to $3.2 \%$ in the control group ( $P<0.01)$. Abnormal MPI, EF $<35 \%$ and high levels of hs-CRP were independent predictors for MCE in the study group. In multivariate analysis only an abnormal MPI remained to be an independent predictor regardless of the size or severity of perfusion abnormalities ( $P<0.005)$. Pts with NSCL on coronary angiography and myocardial perfusion defects have relatively high event rate $(11 \%)$ of MCE over a period of 24 months from the time of MPI.

So, we highly recommend gated SPECT MPI to be performed in cases of NSCL to look for possible ischemia and to avoid life-threatening coronary complications in the forthcoming future. It can also prevent unnecessary repeatedly performed coronary interventions for identifying lesion responsible for angina in NSCL.

KEYWORDS: non-stenotic coronary lesion, ischemia, myocardial perfusion imaging.

CITATION: Cardiol Croat. 2014;9(5-6):192.

\section{Literature}

1. Naya M, Murthy VL, Taqueti VR, et al. Preserved coronary flow reserve effectively excludes high-risk coronary artery disease on angiography. J Nucl Med. 2014;55(2):248-55. 2. Algaisi F, Albadarin F, Jaffery Z, et al. Prognostic predictors and outcomes in patients with abnormal MPI and angiographically insignificant coronary artery disease. J Nuc Cardiol. 2008;15(2):754-61

3. Aude YW, Garza L. How to prevent unnecessary coronary interventions: identifying lesions responsible for ischemia in cath lab. Curr Opin Cardiol. 2003;18(5):394-9. 